\title{
A Close-up Look at Screens for Excluding Asian Citrus Psyllids'
}

\author{
Timothy A. Ebert, Arnold W. Schumann, Laura Waldo, Daniel Stanton, and Philippe \\ Rolshausen ${ }^{2}$
}

Managing the Asian citrus psyllid (Diaphorina citri Kuwayama [Hemiptera: Liviidae]) remains one of the primary challenges in producing marketable citrus fruit in Florida. The insect transmits the bacterial pathogen Candidatus Liberibacter asiaticus (CLas) that causes huanglongbing. Disease management has involved a suite of strategies like clean nursery stock, removing infected trees, and insecticide sprays to control the Asian citrus psyllid. However, the psyllid has developed some degree of insecticide resistance to many insecticides: carbamates, organophosphates, pyrethroids, neonicotinoids, and others. Even low-level resistance that increases the time between exposure and death will increase the number of psyllids that move the disease within and between trees. Building a physical barrier around trees or groves can prevent contact between citrus trees and psyllids. This article is for growers, scientists, and industries that are interested in this approach to protect citrus from huanglongbing.

One strategy to avoid issues with psyllid management using insecticides is to grow trees under protective screen covers. Two approaches use this strategy. One is CUPS (Citrus Under Protective Screen), where the entire grove is enclosed under a screen. The other is IPC (individual protective covers), where individual trees are enclosed in a screen bag during vegetative growth (Qureshi et al. 2019;
Alferez et al. 2020). Our goal was to identify the largest opening in the screen that will exclude psyllids. The smallest dimensions of the psyllid will be either the height or width of the insect. In a sample of 670 psyllids, the average psyllid was 638.6 micrometers tall and 602.4 micrometers wide, with a range of 487.7 to 767.5 micrometers tall by 487.5 to 737.5 micrometers wide.

The screens were PME066 (ULMA S. Coop. Oñati Gipuzkoa); PME096 (ULMA S. Coop.); PME108 (ULMA S. Coop.); Polysack25 (Green.tek, Janesville, WI, USA), HDPE 25 mesh (model WEM2525040000, Ginegar Plastic Products Ltd. Kibbutz Ginegar, Israel); PME1610 (ULMA S. Coop.); Polysack40 (model WEM4025040000, Green. tek, HDPE 40 mesh, Ginegar Plastic Products Ltd.) (Fig. 1). Additional screens were also examined: PolySack 50 (Ginegar Plastic Products Ltd. Kibbutz Ginegar, Israel), Optinet50 (Ginegar Plastic Products Ltd.), and two knitted screens, Code 40 and Code 50 (Knittex division of Multinet (Pty) Ltd, https://www.knittex.co.za). The opening size for the screens is listed in Table 1. Measurements are in micrometers $(\mu \mathrm{m})$, where 1000 micrometers equals 1 millimeter, or 0.039 inches. Knitted screen (Knittex Inc.) used uniform fibers with a mean diameter of 237 micrometers for the Code 40 screen and 242 micrometers for the Code 50 screen. The Knittex website does not advertise screen for

1. This document is SL489, one of a series of the Department of Soil and Water Sciences, UF/IFAS Extension. Original publication date June 2021. Visit the EDIS website at https://edis.ifas.ufl.edu for the currently supported version of this publication.

2. Timothy Ebert, postdoctoral associate, Entomology and Nematology Department; Arnold W. Schumann, professor, Department of Soil and Water Sciences; Laura Waldo, biological scientist III, M.S., Department of Soil and Water Sciences; Daniel Stanton, biological scientist II, Plant Pathology Department; UF/IFAS Citrus Research and Education Center, Lake Alfred, FL; and Philippe Rolshausen, Department of Botany and Plant Sciences, University of California at Riverside, Division of Agriculture and Natural Resources; UF/IFAS Extension, Gainesville, FL 32611.

The Institute of Food and Agricultural Sciences (IFAS) is an Equal Opportunity Institution authorized to provide research, educational information and other services

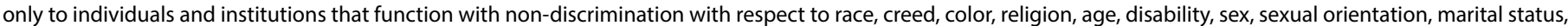

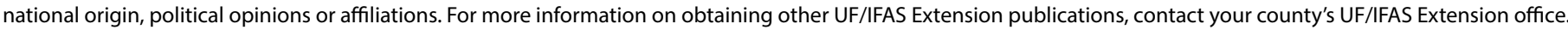
U.S. Department of Agriculture, UF/IFAS Extension Service, University of Florida, IFAS, Florida A \& M University Cooperative Extension Program, and Boards of County Commissioners Cooperating. Nick T. Place, dean for UF/IFAS Extension. 
insect exclusion. Code 40 and Code 50 refer to the percentage of light that is blocked, but this is easily confused with 40- and 50-mesh screens, which refer to the number of openings per inch, wherein smaller mesh sizes indicate larger openings.
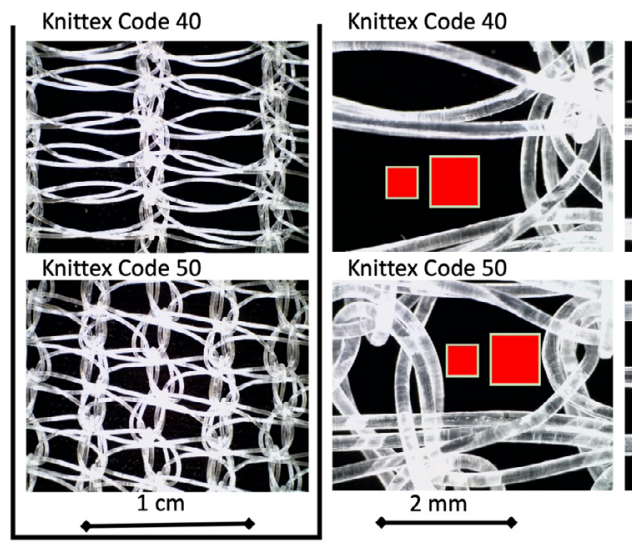

PME066 (17-mesh)
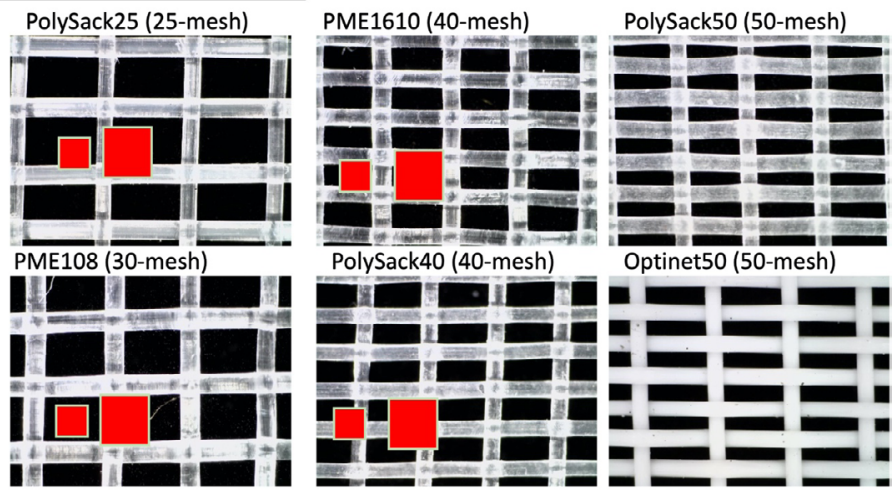

Figure 1. Close-up view of woven screens tested for ability to exclude psyllids. PME1610 and PolySack40 excluded psyllids (see Table 2). Green boxes filled in red represent the minimum and maximum psyllid sizes measured for this study. Code 40 and Code 50 woven screens were not tested, but openings were larger than the largest tested screen. PolySack50 and Optinet50 are 50-mesh screens with openings smaller than the smallest tested screen.

Measurements are in micrometers. 1000 micrometers equals 1 millimeter, or 0.039 inches. The average human hair ranges from 17 to 181 micrometers in diameter (0.00067 to 0.0071 inches). The height of the smallest psyllid measured was 0.019 inches, or $487.5 \mu \mathrm{m}$.

To test the screen, psyllids were collected from the field or a laboratory colony and placed into a small vial. Another vial had a new citrus flush (apical meristem plus 2 or 3 leaves $<30 \%$ fully expanded). The vials were connected, but psyllid movement from one vial to the other was blocked by a screen. Air was pulled across the flush, through the screen, and over the psyllids. Psyllids that could not get through the screen died of dehydration.

Adult psyllids penetrated screen PME066 with 74.5\% able to pass through the screen. Only $7.6 \%$ of psyllids passed PME096. No psyllid passed the screens with the smallest openings (40-mesh) PME1610 and Polysack40 (Table 2). We cannot say that the 40 -mesh screen is psyllid-proof based on these finite laboratory test conditions, but the larger width of the adult psyllids compared to the narrowest dimension of the screen holes means that psyllid penetration is highly unlikely. We were confident enough in its effectiveness to use 40-mesh screen when the screen was replaced at the CUPS grove at the Citrus Research and Education Center.

While we did not test the knitted screen using psyllids, we photographed and measured opening sizes. The opening size in knitted screen is highly variable with regularly spaced large openings. The large openings are roughly trapezoidal. These larger openings were larger than the openings in any of the woven screens that we tested (Table 1, Figure 1).

In this approach to protect citrus, the screen may get stretched through daytime heat, age, and stress from the weight of the screen or wind pushing on the screen (for CUPS) or the tree pushing on the screen (for IPCs). Everything is "flexible" if enough force is applied, and opportunities may develop for an insect to get through if it finds the right spot. Therefore, the openings need to be slightly smaller than the threshold value for excluding psyllids. Furthermore, psyllids range in size just like people do, and it is not possible to test the entire range in sizes. The difference between the current size of the openings and the maximum opening that would still exclude psyllids is a safety margin. The safety margin is estimated by considering the screen as a sieve where large particles (psyllids) stay on one side while smaller ones get through. A regression analysis using data from screens where some psyllids passed through the screen was significant ( $d f 1,2, F=190.9$ $P>F=0.005)$ with the equation "proportion of psyllids passed" $=-0.8728(0.0815)+0.00124(0.00009) \times$ "opening size." The lower $95 \%$ prediction for the short side dimension that would be "psyllid proof" was $495.5 \mu \mathrm{m}$. This was at least $110 \mu \mathrm{m}$ larger than the short side of the screens that did not let psyllids pass.

The PME1610 and Polysack40 screens prevented psyllids from reaching food and water in the arenas. A regression analysis indicated that these screens would keep out all psyllids even if the screen stretches slightly under stress, weathering, and age, or if fibers are out of alignment. However, the efficacy of the screen will be impaired more by distortions in the short dimension. Finally, while tested psyllids came from different hosts there may be even smaller psyllids in different populations of this insect or reared on other hosts. However, smaller psyllids have fewer 
metabolic resources to survive the migration that would take them from their current location to the plants under a protective screen.

We suggest the use of screens with openings of $385 \mu \mathrm{m}$ or less ( $\sim 40$ mesh or more) because these exclude the Asian citrus psyllid. In addition to excluding psyllids, the use of these screens further alters the pest management landscape by excluding larger insects: sharpshooters, stink bugs, weevils, and many lepidopterous pests. The screen excludes some beneficial insects, and that may or may not be a benefit. This approach to pest management can be adapted to other pests and other crops so long as the return on investment is profitable. However, the screen mesh size needs to be adapted to perform properly for each use. The knitted screen we examined would not be suitable for excluding the Asian citrus psyllid because the openings are too large. A more complete description of methods and results for the woven screen can be found in this open-access article: https://academic.oup.com/jee/article/113/4/2026/5840497.

\section{Acknowledgment}

Funding supplied by National Institute of Food and Agriculture grant 2018-70016-27387. Any opinions, findings, conclusions, or recommendations expressed in this publication are those of the author(s) and do not necessarily reflect the view of the US Department of Agriculture. Use of product names is only for accurately reporting methods and is not an endorsement of those products over other similar products.

\section{Literature Cited}

Alferez, F., S. Gaire, U. Albrecht, O. Batuman, J. Qureshi, and M. Zekri. 2020. "Research Update on Individual Protective Covers." Citrus Industry. 101 (11). https://citrusindustry.net/2020/11/24/ research-update-on-individual-protective-covers/

Qureshi, J., L. Stelinski, and F. Alferez. 2019. "HLB Reduction Strategies." Citrus Industry 100 (1). https://citrusindustry.net/2019/01/02/hlb-reduction-strategies/ 
Table 1. Characterization of eight woven screens and two knitted screens based on hole size and fiber diameters. The opening size can be compared to the size of $D$. citri, the smallest of which measured $487.5 \mu \mathrm{m}$ wide and $487.5 \mu \mathrm{m}$ high. Woven screens are sold based on mesh size. The largest holes in knitted screen were roughly trapezoidal.

\begin{tabular}{|c|c|c|c|c|c|c|}
\hline \multirow{2}{*}{$\begin{array}{l}\text { Screen } \\
\text { Name }\end{array}$} & \multirow{2}{*}{$\begin{array}{l}\text { Advertised } \\
\text { Mesh Size }\end{array}$} & \multicolumn{2}{|c|}{ Hole Size $(\mu \mathrm{m})$} & \multicolumn{2}{|c|}{ Fiber Diameter $(\mu \mathrm{m})$} & \multirow{2}{*}{\begin{tabular}{|l} 
Calculated \\
Mesh
\end{tabular}} \\
\hline & & Short Side & Long Side & Short Side & Long Side & \\
\hline PME066 & 17 & 1303.0 & 1383.8 & 370.1 & 317.9 & 15.2 \\
\hline PME096 & 20 & 788.9 & 1438.0 & 347.0 & 314.1 & 23.1 \\
\hline Polysack25 & 25 & 675.7 & 1094.0 & 243.2 & 321.8 & 25.5 \\
\hline PME108 & 30 & 732.9 & 993.6 & 352.3 & 321.8 & 24.1 \\
\hline PME1610 & 40 & 376.1 & 801.7 & 279.5 & 276.9 & 38.7 \\
\hline Polysack40 & 40 & 384.3 & 833.3 & 258.0 & 282.3 & 39.6 \\
\hline Polysack50 & 50 & 223.9 & 838.3 & 233.3 & 259.2 & 55.6 \\
\hline \multirow[t]{3}{*}{ Optinet50 } & 50 & 227.1 & 903.4 & 252.6 & 237.6 & 52.9 \\
\hline & \multicolumn{3}{|c|}{ Average Hole Size $(\mu \mathrm{m})$} & \multicolumn{3}{|c|}{ Maximum Hole Size $(\mu \mathrm{m})$} \\
\hline & Length & Short & Long & Length & Short & Long \\
\hline Code 40 & 5563.9 & 886.1 & 1719.4 & 6291.0 & 1319.0 & 2199.0 \\
\hline Code 50 & 2028.0 & 998.7 & 1739.7 & 2797.0 & 1364.1 & 2280.0 \\
\hline
\end{tabular}

Table 2. An estimated percentage of $D$. citri able to pass through screens with different-sized openings and the $95 \%$ confidence interval for this estimate. Fraction is the ratio of the smallest screen hole dimension divided by the smallest psyllid width dimension.

\begin{tabular}{|l|l|l|l|l|l|}
\hline & Psyllids & Percentage & 95\% Confidence Interval & \\
\hline Screen & Tested & Passed & Low & High & Fraction \\
\hline PME066 & 184 & 74.5 & 67.8 & 80.4 & 2.7 \\
\hline PME096 & 1488 & 7.6 & 6.3 & 9.0 & 1.6 \\
\hline PolySack25 & 275 & 1.1 & 0.3 & 2.9 & 1.4 \\
\hline PME108 & 311 & 0.3 & 0.0 & 1.5 & 1.5 \\
\hline PME1610 & 334 & 0.0 & 0.0 & 1.1 & 0.8 \\
\hline PolySack40 & 273 & 0.0 & 0.0 & 1.4 & 0.8 \\
\hline
\end{tabular}

